\title{
Las células dendríticas generadas en presencia de vitamina D3 y activadas con lipopolisacáridos incrementan la producción de IL-1 $\beta$, IL-8 e IL-10 y disminuyen su capacidad de inducir LT CD4 ${ }^{+} \mathrm{CD}^{2} 5^{\mathrm{hi}} \mathrm{Foxp}^{+}$
}

\begin{abstract}
Sindy M. Muñoz, Luz Stella Rodríguez
Instituto de Genética Humana, Facultad de Medicina, Pontificia Universidad Javeriana, Bogotá, D.C., Colombia

Introducción. La vitamina D3 actúa como modulador de algunas células del sistema inmunitario, incluidas las células dendríticas. Varios estudios han reportado su importancia en la generación in vitro de células dendríticas tolerogénicas, similares en cuanto a fenotipo y función a las células dendríticas dérmicas CD141 productoras de IL-10 e inductoras de linfocitos T reguladores CD4+.

Objetivo. Se compararon el fenotipo y las citocinas producidas por las células dendríticas generadas en ausencia o en presencia de la vitamina D3, y maduradas con lipopolisacáridos, así como su habilidad de inducir linfocitos $T$ reguladores a partir de linfocitos T CD4+ vírgenes alogénicos.

Materiales y métodos. Se aislaron células mononucleares de sangre periférica para seleccionar monocitos CD14+ y diferenciarlos in vitro de las células dendríticas en presencia o en ausencia de vitamina D3, y madurarlas con lipopolisacáridos. Se analizaron el fenotipo y los niveles de las citocinas en los sobrenadantes de cultivo. Se hizo un cocultivo de las células dendríticas con linfocitos T CD4+ vírgenes alogénicos y se determinaron las frecuencias de LTreg (vírgenes activados).

Resultados. Las células dendríticas no estimuladas generadas con la vitamina D3 conservaron el CD14. Al activarlas con lipopolisacáridos, expresaron bajos niveles de C83, CD83 y CD86, HLA-DR, cantidades elevadas de IL-1 $\beta$, IL-8 e IL-10, y una tendencia a la disminución de IL-6, IL-12p70 y TGF$\beta 1$ con respecto a las que no habían sido tratadas con la vitamina. La frecuencia de los LTreg vírgenes fue similar, aunque se observó una tendencia de las células dendríticas inmaduras generadas con la vitamina a inducir LTreg activados.

Conclusión. Las células dendríticas generadas con vitamina D3 y tratadas con lipopolisacáridos presentaron un fenotipo 'semimaduro', así como la capacidad de secretar citocinas antiinflamatorias y citocinas promotoras de la reacción inflamatoria. Además, no se aumentó su capacidad de promover la polarización de LTCD4+ vírgenes alogénicos hacia LTreg.
\end{abstract}

Palabras clave: células dendríticas, lipopolisacáridos, citocinas, linfocitos T.

doi: http://dx.doi.org/10.7705/biomedica.v36i2.2885

Dendritic cells generated in the presence of vitamin D3 and stimulated with lipopolysaccharide secrete IL-8, IL-1 $\beta$, IL-10 and induce relatively low levels of CD4+CD25hiFoxp3+ T cells

Introduction: Vitamin D3 (VD3) has been described as a modulator of immune system cells, including dendritic cells (DC). Previous studies have shown its importance in in vitro generation of tolerogenic DC, which have a similar function and phenotype to that of CD141 dermal DCs that produce IL-10 and induce (LTreg) CD4+ T regulator cells.

Objective: This paper presents a study that compares the phenotype and cytokines produced by DC generated in presence and absence of VD3, which were matured with lipopolysaccharide (LPS), and their ability to induce LTreg from naïve allogeneic CD4+ T cells.

Materials and methods: In order to compare them, peripheral blood mononuclear cells were isolated to select monocytes CD14+ T cells and differentiate them in vitro from DC in the presence and absence of VD3, and to mature them with LPS. Phenotype and cytokine levels were also analyzed in the culture supernatants. Dendritic cells were then co-cultured with naïve allogeneic CD4+ T cells and the frequencies of LTreg were determined (naïve-activated).

Results: The results showed that unstimulated DC generated with VD3 kept the CD14. When activated with LPS, they expressed lower levels of C83, CD83 and CD86; HLA-DR; higher amounts of IL-1 $\beta$,

\section{Contribución de los autores:}

Las dos autoras participaron en la planeación y ejecución del estudio y en la escritura del manuscrito. 
IL-8, IL-10, and tended to lessen IL-6, IL-12p70 and TGF- $\beta 1$, compared to DCs not treated with VD3. The frequency of naïve LTreg was similar, although immature DC generated with VD3 tended to induce activated LTregs.

Conclusion: Based on these results, it is possible to conclude that DCs generated with VD3 and treated with LPS presented a 'semi-mature' phenotype, and were able to secrete pro-inflammatory and anti-inflammatory cytokines. Besides, they did not increase their capacity to promote the polarization of naïve allogenic CD4+ T cells towards LTregs.

Key words: Dendritic cells, lipopolysaccharides, cytokines, T-Lymphocytes. doi: http://dx.doi.org/10.7705/biomedica.v36i2.2885

Un aspecto fundamental de las células dendríticas (CD) es la posibilidad de generarlas in vitro a partir de monocitos CD14 en presencia de GranulocyteMacrophage Colony-Stimulating Factor, (GM-CSF) e interleucina 4 (IL-4), y modular su estado de diferenciación y maduración, lo que permite obtener células dendríticas inmunogénicas asociadas a respuestas efectoras o células dendríticas tolerogénicas.

Estas últimas se caracterizan por tener un fenotipo 'semimaduro', resistencia a la maduración, alta producción de citocinas antiinflamatorias y la habilidad de inducir linfocitos $T$ reguladores (LTreg) $(1,2)$. Varias citocinas, como la IL-10 y el TGF- $\beta$ (Transforming Growth Factor Beta), al igual que agentes farmacológicos como la rapamicina, la dexametasona o la vitamina D3 (VD3), inducen células dendríticas con propiedades tolerogénicas in vitro (3).

Las células dendríticas generadas a partir de monocitos en presencia de vitamina D3 (CDVD3) presentan un fenotipo tolerogénico estable, caracterizado por la disminución de la expresión de HLA-DR (Human Leukocyte Antigen - antigen D Related) y de moléculas coestimuladoras, al igual que un incremento en la relación de las interleucinas secretadas IL-10 e IL-12p70 (4). Además, este perfil de las células dendríticas tolerogénicas se ha relacionado con la inducción de los linfocitos T FoxP3 que secretan IL-10, expresan CTLA-4 (Cytotoxic T-Lymphocyte-Associated Protein 4) y son capaces de suprimir la proliferación de linfocitos $T$ efectores, lo cual se asocia con una reacción reguladora (5).

En el 2012, Chu, et al., demostraron que las células dendríticas derivadas de monocitos y generadas en presencia de vitamina D3 tienen un fenotipo y

\section{Correspondencia:}

Luz Stella Rodríguez, Instituto de Genética Humana, Pontificia Universidad Javeriana, Carrera $7 \mathrm{~N}^{\circ}$ 40-62, edificio 32, Bogotá, D.C., Colombia

Teléfono: (571) 320 8320, extensión 2790

luz-rodriguez@javeriana.edu.co

Recibido: 16/06/15; aceptado: 19/10/15 una función semejantes a las células dendríticas dérmicas (CDD) CD141+, las cuales se consideran como el mayor grupo de células dendríticas productoras de IL-10 residentes en la piel e inductoras de LTreg supresores de inflamación (6). Por lo tanto, estas células dendríticas generadas en presencia de vitamina D3 podrían emplearse como tratamiento celular para enfermedades autoinmunitarias o para evitar el rechazo a los trasplantes.

A pesar de los hallazgos mencionados, ha surgido la controversia en torno a la caracterización de las CDD CD141 reportadas por Chu, et al. en el 2012, ya que según el estudio realizado por Haniffa, et al., esta población corresponde a células dendríticas sanguíneas que expresan CD14 relacionadas con monocitos que también expresan CD141 y producen IL-1, IL-6 e IL-10 como reacción a estímulos inflamatorios (7).

Se desconoce qué otras citocinas pueden producirse a partir de las células dendríticas generadas en presencia de vitamina D3 y cómo podrían afectar la capacidad de las células dendríticas de polarizar la respuesta de los linfocitos T vírgenes alogénicos hacia un perfil regulador.

Por lo tanto, en este trabajo se evaluó el efecto de la vitamina D3 tanto en el fenotipo como en la producción de citocinas adicionales a las reportadas tradicionalmente (IL-10 e IL-12p70), así como su capacidad de inducir LTreg a partir de linfocitos $T$ CD4+ vírgenes alogénicos. Los datos obtenidos indicaron que las células dendríticas generadas con vitamina D3 y tratadas con lipopolisacáridos, presentaban un fenotipo 'semimaduro' reflejado en la expresión de CD14 y los bajos niveles de CD83, CD86 y HLA-DR. Su patrón de citocinas secretadas incluyó niveles elevados de IL-1 $\beta$, IL-8 e IL-10, comparados con los de las células dendríticas generadas en ausencia de vitamina D3. Además, se observó una tendencia de las células dendríticas inmaduras generadas con vitamina D3 a inducir altos porcentajes de LTreg activados, efecto que disminuyó con su maduración. 


\section{Materiales y métodos}

\section{Aislamiento de monocitos y generación de células dendríticas}

Se tomó una muestra de sangre total de voluntarios adultos sanos que previamente firmaron el consentimiento informado aprobado por el Comité de Ética de la Pontificia Universidad Javeriana.

Las muestras se centrifugaron para obtener el plasma y la fracción celular a partir de la cual se separaron las células mononucleares de sangre periférica, utilizando el gradiente de densidad de Ficoll Hypaque (GE Healthcare Bio-Sciences Corp., Piscataway, NJ, USA). Las células se lavaron dos veces con RPMI 1640 (Gibco-BRL, Gaithersburg, MD) con suplemento de $2 \mathrm{mM}$ de L-glutamina, 100 $\mathrm{U} / \mathrm{ml}$ de penicilina, $100 \mu \mathrm{g} / \mathrm{ml}$ de estreptomicina (Gibco-BRL, Gaithersburg, MD) y plasma autólogo al $1 \%$ (medio completo). Posteriormente, se resuspendieron en solución amortiguadora de fosfato salino (PBS) con $2 \mathrm{mM}$ de EDTA (Sigma Aldrich, St. Louis, MO) más 0,5\% de albúmina humana (Biotest, Pharma, Dreieich, Germany). Los monocitos se purificaron mediante separación inmunomagnética usando selección positiva con microperlas CD14 (Miltenyi Biotec, Auburn, CA) según las instrucciones del fabricante. Las células CD14+ purificadas (mediana de pureza: $95 \%$; rango: $91,3-99,2 \% ; n=8$ ) se usaron para originar las células dendríticas.

Para generar las células dendríticas inmaduras, las células CD14+ se cultivaron durante seis días a una densidad de 1 millón $/ \mathrm{ml}$ y a $37^{\circ} \mathrm{C}$, y $5 \%$ de $\mathrm{CO}_{2}$ en medio completo más $1,000 \mathrm{U} / \mathrm{ml}$ de $\mathrm{GM}$ CSF e IL-4 (Prepotech, México); en el día 3 se agregaron más citocinas a la misma dosis inicial.

Para la generación de las células dendríticas inmaduras (CDI) en ausencia o en presencia de vitamina D3 (VD3I), en el día 5 se adicionaron volúmenes iguales de etanol absoluto (Sigma Aldrich, St. Louis, $\mathrm{MO}$ ), usado como diluyente de la vitamina D3, o 100 nM de vitamina D3 (Sigma Aldrich, St. Louis, $\mathrm{MO}$ ) dependiendo el diseño del experimento.

Todos los reactivos utilizados fueron negativos para la presencia de lipopolisacáridos, lo cual se verificó utilizando un kit comercial (BioWhittaker, Inc., Walkersville, MD).

En el día 6, el fenotipo de las células dendríticas inmaduras obtenidas se determinó mediante citometría de flujo, usando el siguiente panel de anticuerpos: CD14-V500 (BD Biosciences; Clon
M5E2; Catálogo No. 561391), HLA-DR-PerCP Cy5.5 (BD Biosciences; Clon L243; Catálogo No. 339194), CD83-PE (BD Pharmingen; Clon HB15e; Catálogo №556855) y CD86-APC (BD Pharmingen; Clon FUN-1; Catálogo № 555660).

Después de la tinción, las células se lavaron y se fijaron con paraformaldehído al $1 \%$ (Electron Microscopy Sciences, Washington, PA), se hizo su recuento en el citómetro de flujo LSRFORTESSA (BD Bioscience, San José, CA, USA) y se analizaron con el programa FACSDiva versión 8.0.

Las células muertas y los restos celulares se excluyeron con base en el análisis de su tamaño. En algunos experimentos se evaluó la expresión de CD274- FITC (BD Pharmingen; Clon MIH1; Catálogo No. 558065) y de CD141-PE (BD Pharmingen; Clon 1A4; Catálogo No. 559781). Se ajustaron los parámetros de lectura del citómetro para el análisis de los experimentos.

Una vez obtenidas las células dendríticas inmaduras, se lavaron, se contaron y se cultivaron en medio completo sin plasma, con $1.000 \mathrm{U} / \mathrm{ml}$ de GM-CSF e IL-4 (Prepotech, México) y $1 \mu \mathrm{g} / \mathrm{ml}$ de lipopolisacáridos (LPS de Escherichia coli, serotipo 055:B5; Sigma-Aldrich, St. Louis, MO, USA) para estimular su maduración o para su respectivo control con PBS, en presencia o en ausencia de 100 nM de vitamina D3 durante 24 horas.

El fenotipo de las células dendríticas maduras se determinó por citometría de flujo usando el mismo panel de anticuerpos descrito anteriormente. Los resultados de la citometría para el fenotipo de las poblaciones de células dendríticas se reportaron como la intensidad media de fluorescencia de cada marcador y como el porcentaje de células que expresaban un marcador o combinaciones de diferentes marcadores.

\section{Medición de citocinas en los sobrenadantes de cultivo de células dendríticas}

Los sobrenadantes de cada una de las poblaciones de células dendríticas inmaduras y maduras se almacenaron a $-20^{\circ} \mathrm{C}$ hasta el momento de descongelarlos para la determinación cuantitativa de IL-1 $\beta$, IL-6, IL-8, IL-10, IL-12p70 y TNFa mediante citometría de flujo, y utilizando la técnica de microesferas del estuche comercial Cytometric Bead Array Human Inflammation Kit (BD Biosciences, San José, CA); el análisis se hizo con el programa FCAP Array, versión de Windows (BD Biosciences, San José, CA). El límite de detección dependió de cada citocina analizada y varió entre 1,9 y $7,2 \mathrm{pg} / \mathrm{ml}$. 
El TGF- $\beta 1$ total se cuantificó mediante ELISA siguiendo las instrucciones del estuche comercial (TGF- $\beta 1$, Duoset kit R\&D Systems, Minneapolis, MN - límite de detección de 31,2pg/ml) y se analizó mediante la determinación de la densidad óptica a $450 \mathrm{~nm}$ en el lector Thermo Scientific Multiskan EX (Thermo Scientific; Waltham, MA, USA).

\section{Medición de la viabilidad celular mediante la liberación de deshidrogenasa láctica}

La pérdida de la viabilidad celular se registró con la medición de la liberación de la deshidrogenasa láctica en el medio de cultivo, utilizando un estuche comercial de Roche (Roche Diagnostics, Mannheim, Germany) y siguiendo las indicaciones del fabricante.

\section{Cocultivo de células dendríticas y linfocitos $T$ CD4+ vírgenes alogénicos}

Los linfocitos $T$ vírgenes $\mathrm{CD}^{+} \mathrm{CD}^{+} 5 \mathrm{RA}^{+}$se purificaron a partir de células mononucleares de sangre periférica mediante separación inmunomagnética por selección negativa, utilizando el estuche comercial Naive $C D 4^{+} T$ Cell Isolation Kit II (Miltenyi Biotec, Auburn, CA) y siguiendo las instrucciones del fabricante. La mediana de la pureza de la población obtenida fue de $94,7 \%$ y el rango fue de $88,0-95,4 \%(n=5)$.

Las células dendríticas tratadas con lipopolisacáridos durante 24 horas o con el PBS de control, se sometieron a cocultivo en una relación de 1:10 con linfocitos T CD4+ vírgenes alogénicos purificados durante siete días a $37^{\circ} \mathrm{C}+\mathrm{CO}_{2}$ al $5 \%$.

Posteriormente, las poblaciones se recuperaron y se tiñeron con el siguiente panel de anticuerpos: anti CD4-PerCP-Cy5.5 (BD Biosciences; Clon SK3; Catálogo No. 341654), anti CD25- APC (BD Biosciences; Clon M-A251; Catálogo No. 555434) y anti CD45RA-FITC (BD Biosciences; Clon HI100; Catálogo No. 555488) durante 20 minutos a temperatura ambiente.

Después del lavado, las células se trataron con solución de fijación y permeabilización (eBioscience, San Diego, CA) durante 30 minutos a $4{ }^{\circ} \mathrm{C}$ y se lavaron con $1 \mathrm{ml}$ de solución tampón de lavado. Después, el anticuerpo anti-Foxp3-PE (eBioscience; Clon PCH101; Catálogo No. 124776-42) se adicionó e incubó durante 30 minutos a temperatura ambiente. Por último, las células se lavaron y resuspendieron en $300 \mu \mathrm{l}$ de solución de lavado, y se analizaron en el citómetro de flujo
LSRFORTESSA (BD Bioscience, San José, CA, USA), y se analizaron con el programa FACSDiva, versión 8.0 (BD Bioscience, San José, CA, USA).

\section{Análisis estadísticos}

Los análisis estadísticos se hicieron con el programa GraphPad Prism, versión 5.0 (GraphPad Software, Inc., San Diego, CA) mediante pruebas no paramétricas. Las diferencias entre los datos no pareados y los pareados se determinaron con las pruebas de Mann-Whitney y Wilcoxon, respectivamente. Se consideró estadísticamente significativo un valor de $p<0,05$. A menos que se especifique lo contrario, se muestran las medianas de los experimentos.

\section{Resultados}

\section{Las células dendríticas generadas en presencia de vitamina D3 presentaron un fenotipo 'semimaduro'.}

Con el fin de determinar el efecto de la vitamina D3 sobre el fenotipo de las células dendríticas generadas in vitro a partir de monocitos, se evaluó la expresión de moléculas de superficie relacionadas con la activación y la diferenciación. Para ello, se aislaron y cultivaron monocitos CD14+ con citocinas de diferenciación en presencia o en ausencia de vitamina D3 durante seis días, para obtener células dendríticas inmaduras (VD3 I-CD I), las cuales se estimularon posteriormente con lipopolisacáridos durante 24 horas.

Tanto en las células dendríticas inmaduras (VD3 I-CD I) como en las estimuladas con lipopolisacáridos (CDLPS-VD3LPS) y sus respectivos controles (CDCX-VD3CX), se evaluó la expresión de CD14, HLA-DR, CD83 y CD86 por citometría de flujo (figura 1A).

Como se esperaba, la maduración con lipopolisacáridos de las células dendríticas generó un incremento significativo en la frecuencia de las células HLA-DR+ (figura 1C) y en las que expresaban simultáneamente CD83 y CD86 (figura 1D); sin embargo, la presencia de vitamina D3 generó cambios fenotípicos particulares. El análisis de las poblaciones inmaduras en el día 6 mostró una diferencia estadística en el porcentaje de células $\mathrm{CD}^{+} 4^{+}$, el cual fue mayor en las células dendríticas inmaduras generadas en presencia de vitamina D3 (figura 1B). Asimismo, se evidenció un incremento significativo en el porcentaje de células que expresaban CD14 (figura 1B) y en la intensidad media de fluorescencia (figura 2A) al comparar las células dendríticas no estimuladas (VD3CX Vs. 
A

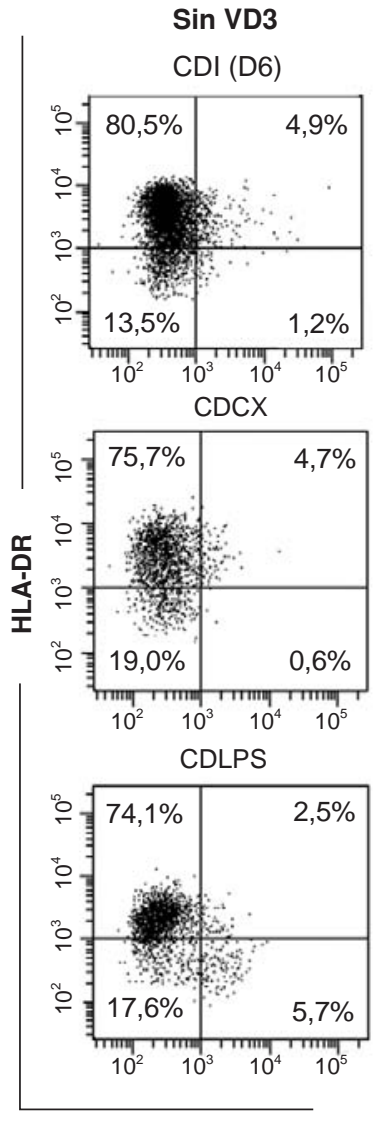

Con VD3
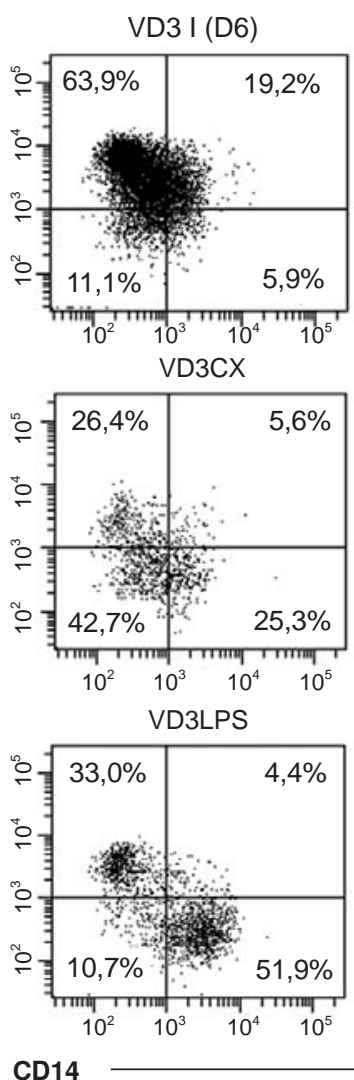

D3
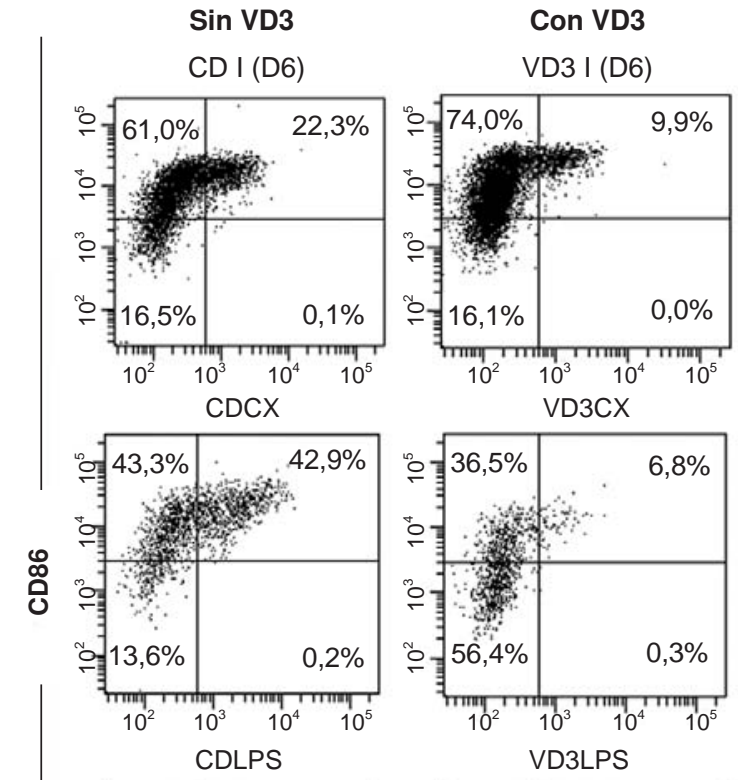

Con VD3
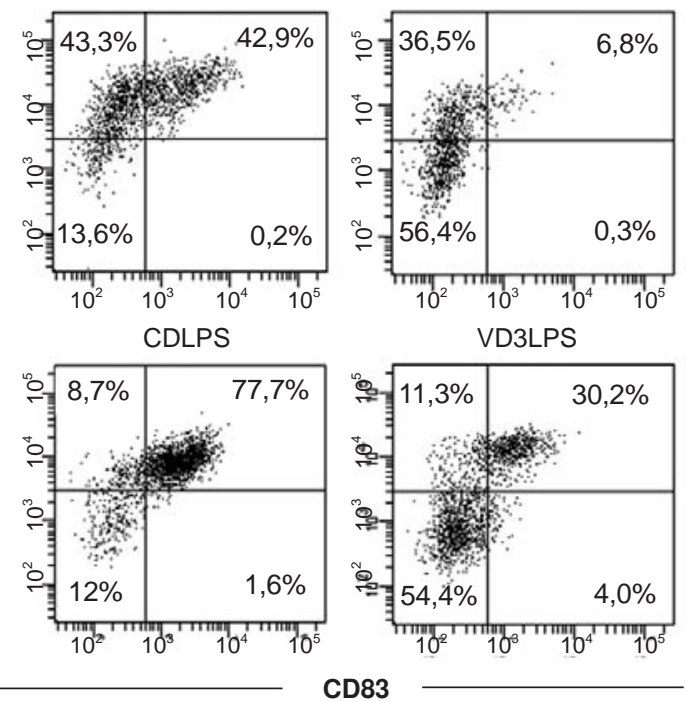

B

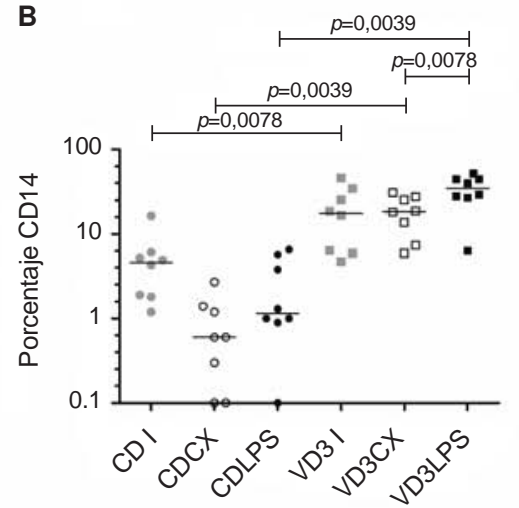

\section{C}

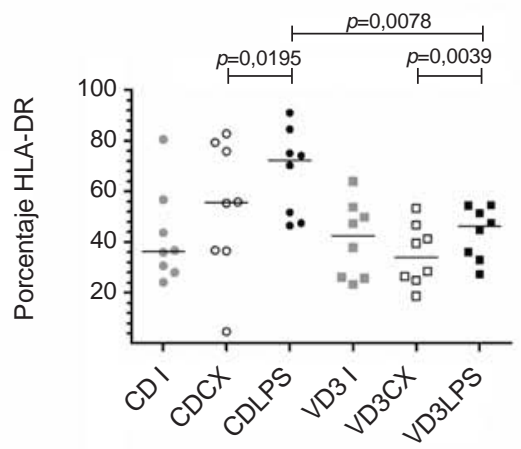

D

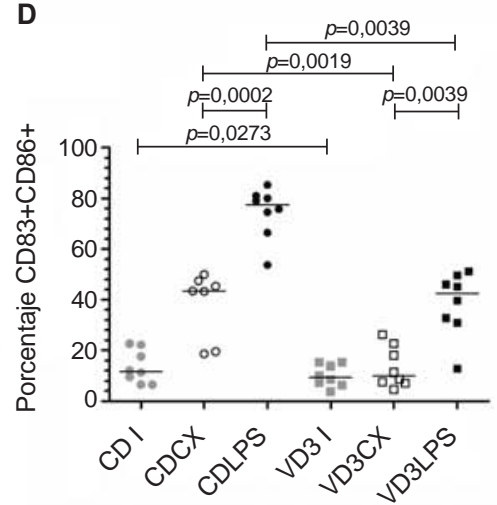

Figura 1. Caracterización fenotípica de las células dendríticas (CD) generadas en ausencia o en presencia de la vitamina D3 (VD3). Se aislaron monocitos de células mononucleares de sangre periférica y se cultivaron durante seis días con IL-4 y GM-CSF para obtener células dendríticas inmaduras (D6). La adición de $100 \mathrm{nM}$ de vitamina D3 al cultivo en el día 5, dio origen a las células dendríticas VD3I. Posteriormente, las células dendríticas generadas en ausencia (CD I) o en presencia de vitamina D3 (VD3 I), se maduraron con lipopolisacáridos (LPS) durante 24 horas. (A) Las gráficas muestran un experimento representativo de los ocho llevados a cabo. Se observa el porcentaje de células que expresaron (B) CD14, (C) HLA-DR y (D) CD83+CD86+.

CDCX) y las estimuladas con lipopolisacáridos (VD3LPS Vs. CDLPS). Estos resultados sugieren que la presencia de vitamina D3 durante el proceso de generación de las células dendríticas mantiene la expresión del CD14, independientemente de la maduración con lipopolisacáridos.
Con respecto a la expresión de HLA-DR, la maduración con lipopolisacáridos reflejó una disminución en el porcentaje de células VD3LPS $\mathrm{HLA}^{-\mathrm{DR}^{+}}$en comparación con las CDLPS (figura 1C). Inesperadamente, la intensidad media de fluorescencia del marcador mostró un leve aumento 


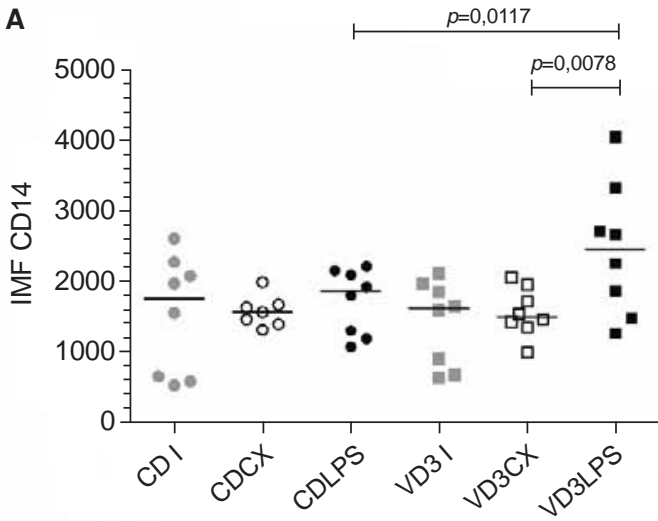

C
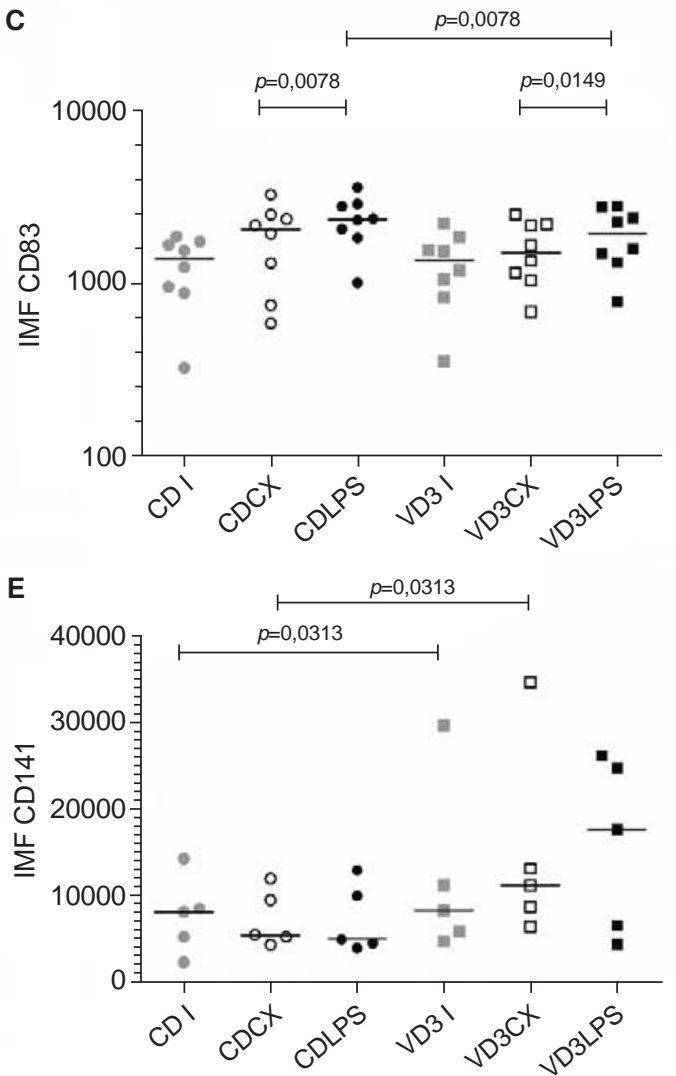
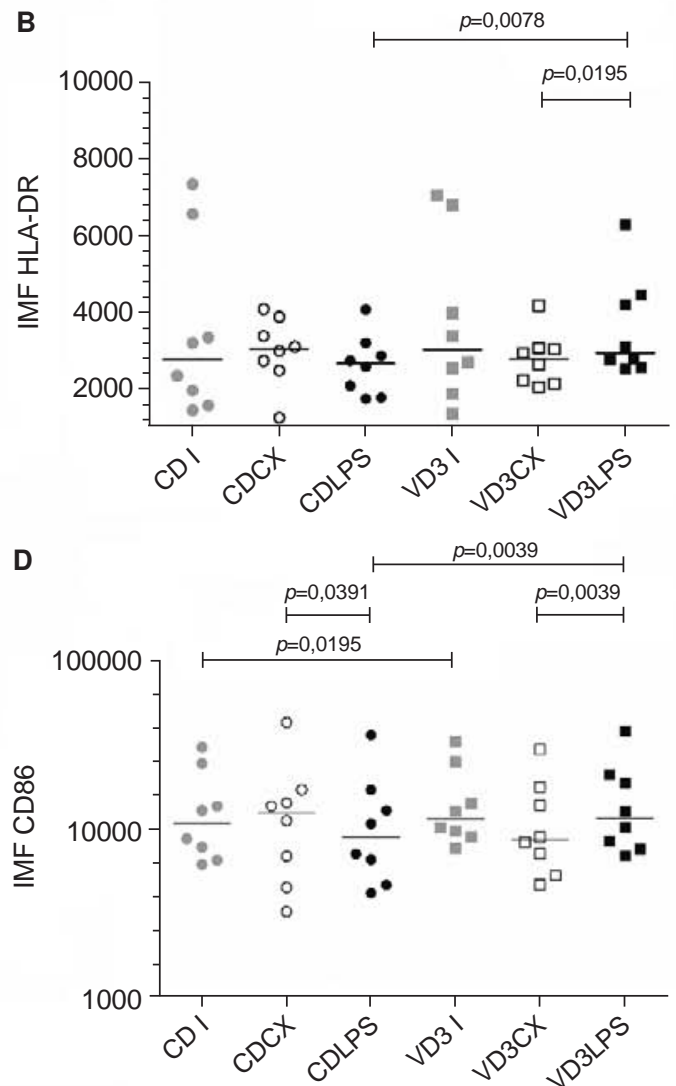

$\mathbf{F}$

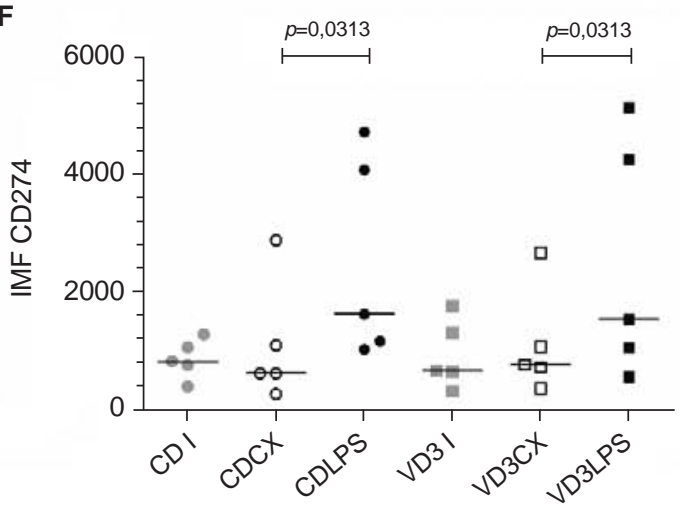

Figura 2. Intensidad media de fluorescencia de los marcadores evaluados. La de los marcadores (A) CD14, (B) HLA-DR, (C) CD83, (D) CD86, (E) CD141 y (F) CD274, se analizó mediante citometría de flujo en las poblaciones sin estímulo y las estimuladas. Cada punto representa un experimento de un total de ocho. La línea horizontal representa la mediana. Las diferencias se determinaron con la prueba de Wilcoxon. El valor de $\mathrm{p}<0,05$ se consideró significativo.

$(9,7 \%)$ en la población VD3LPS comparada con la CDLPS (figura 2B). En conclusión, la presencia de vitamina D3 durante la generación de las células dendríticas disminuyó el porcentaje de células dendríticas HLA-DR+, pero generó un leve aumento de la expresión del marcador.

En cuanto al porcentaje de células que expresaban simultáneamente CD83 y CD86, se evidenció una disminución significativa de estos marcadores asociada al tratamiento con vitamina D3 tanto en células inmaduras (VD3I Vs, CDI) como en las estimuladas con lipopolisacáridos (VD3LPS Vs. CDLPS) y sus respectivos controles (VD3CX Vs. CDCX) (figura 1D).

Cuando se analizó la intensidad media de fluorescencia de las CD86 en las poblaciones, se demostró un aumento significativo relacionado con el tratamiento con vitamina D3 en la población 
estimulada con lipopolisacáridos (figura 2D), así como una disminución estadística de la intensidad media de fluorescencia de las CD83 (figura 2C) con respecto a las células dendríticas maduradas que no se habían generado con vitamina D3. Además, se evaluó el marcador CD141 $(n=5$, figura $2 \mathrm{E}$ ), molécula relacionada con las células dendríticas dérmicas CD141+ productoras de IL10 que pueden generarse a partir del tratamiento con vitamina D3 (8). Los resultados mostraron un incremento significativo en la intensidad media de fluorescencia de las CD141 en las células dendríticas tratadas con vitamina D3 inmaduras en el día 6 (VD3I) y en el 7 (VD3CX), comparadas con las que no habían sido generadas con vitamina D3. Además, se evidenció una tendencia al aumento en la población generada con vitamina D3 y madurada con lipopolisacáridos comparada con la que no había sido tratada con dicha vitamina (CDLPS Vs. VD3LPS).

Con respecto a las moléculas 'coinhibitorias', teniendo en cuenta el papel del PD-L1 (Programmed Death-Ligand 1), también conocido como CD274 (Cluster of Differentiation 274), en las células presentadoras de antígeno con características tolerogénicas, se analizó su expresión en las poblaciones de células dendríticas. En los cinco experimentos llevados a cabo se evidenció un incremento significativo de la intensidad media de fluorescencia de este marcador en las células dendríticas maduradas con lipopolisacáridos, independientemente de la presencia de vitamina D3 (figura 2F).

La vitamina D3 no indujo cambios en la viabilidad celular, ya que la liberación de deshidrogenasa láctica no se vio alterada por su presencia, en comparación con las células dendríticas generadas en presencia del etanol empleado como vehículo (no se presentan los datos).

\section{Las células dendríticas tratadas con la vitamina D3 y maduradas con lipopolisacáridos producen más IL-1ß, IL-8 e IL-10.}

Para identificar el perfil de citocinas secretadas por la población de células dendríticas tratadas con vitamina $\mathrm{D} 3$, se midieron las citocinas IL$1 \beta$, IL-6, IL-8 y IL-12p70, y los factores TNF-a y TGF- $\beta 1$ en los sobrenadantes de cultivo de los experimentos descritos anteriormente (figura 3). En las poblaciones de células dendríticas inmaduras, generadas con o sin vitamina D3, en el día 6 se encontraron niveles similares en todas las citocinas evaluadas, excepto para la IL-8, pues las células dendríticas generadas en presencia de vitamina D3 presentaron una disminución significativa de dicha citocina en comparación con las células dendríticas generadas con etanol $(n=8)$.

Como se esperaba, en la población de células dendríticas generadas sin vitamina D3, la maduración con lipopolisacáridos incrementó la producción de la mayoría de las citocinas evaluadas (figura 3); sin embargo, las células dendríticas tratadas con vitamina D3 y maduradas con lipopolisacáridos secretaron niveles superiores de IL-1 $\beta$ e IL-8, y, como ya se ha descrito, de IL-10, cuya producción también se incrementó significativamente en las células tratadas con vitamina D3 sin madurar (VD3CX Vs. CDCX) (figura 3A-C).

En cuanto a la producción de IL-6, la presencia de vitamina D3 generó un aumento significativo al comparar las poblaciones no estimuladas con lipopolisacáridos (CDCX Vs. VD3CX) (figura 3D). Al evaluar los niveles de IL-12p70, se observó un aumento significativo asociado a la maduración con lipopolisacáridos únicamente en las células dendríticas generadas sin vitamina D3, y una tendencia a la disminución de su producción al comparar VD3LPS con CDLPS (figura 3F). Con respecto al TGF- $\beta 1$, se encontró una disminución significativa ( $8 \%$ ) al comparar las células control (CDCX) con las expuestas a lipopolisacáridos (CDLPS); además, se observó una tendencia a la disminución en los niveles de esta citocina en todas las poblaciones de células dendríticas generadas en presencia de vitamina D3 $(n=7)$ (figura 3G).

\section{Las células dendríticas generadas con la vitamina D3 y maduradas con lipopolisacáridos disminuyen su capacidad de inducir LTreg activados $\left(C D 4^{+} C D 45 R A^{\text {low }} C D 25^{\text {hi }} \mathrm{FOXP3}^{+}\right)$a partir de linfocitos T CD4+ vírgenes alogénicos.}

Dadas las características fenotípicas y funcionales de las células dendríticas tratadas con vitamina D3, se evaluó si esta población en particular podría dirigir la diferenciación de linfocitos T CD4 vírgenes alogénicos hacia LTreg. Para ello, las células dendríticas generadas en ausencia o en presencia de vitamina D3 y no estimuladas y estimuladas con lipopolisacáridos, se sometieron a cocultivo con linfocitos T CD4 vírgenes alogénicos. En el día 7, las células se recuperaron y se marcaron con anticuerpos contra CD4, CD45RA, CD25 y FoxP3 para su análisis fenotípico por citometría de 
A

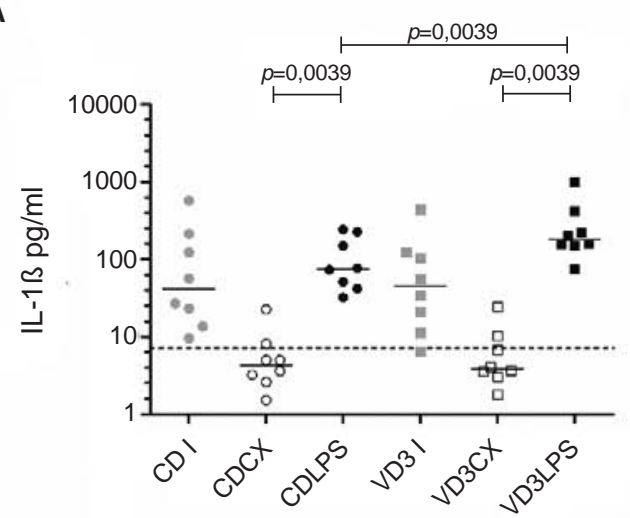

C
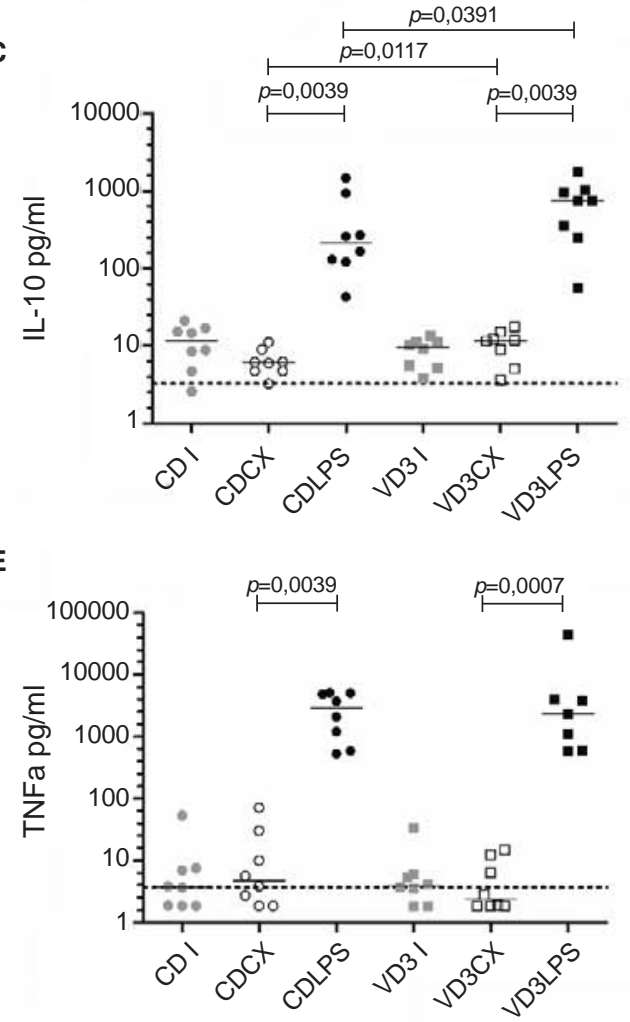

B

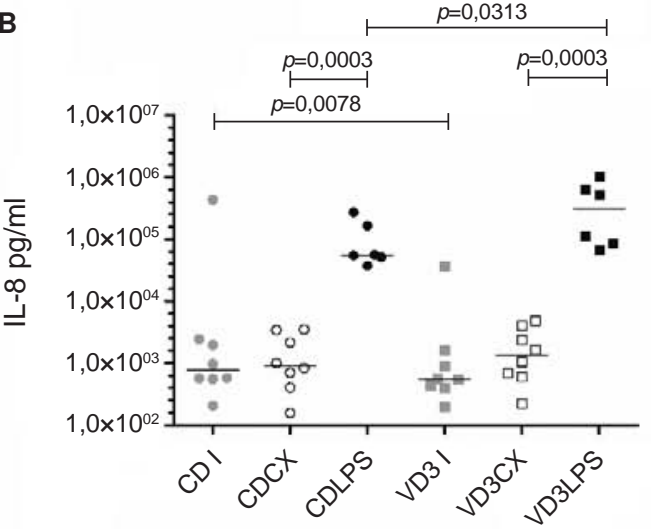

D

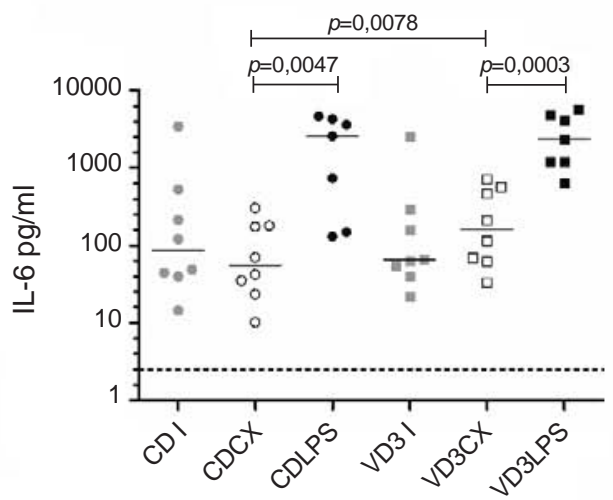

$\mathbf{F}$

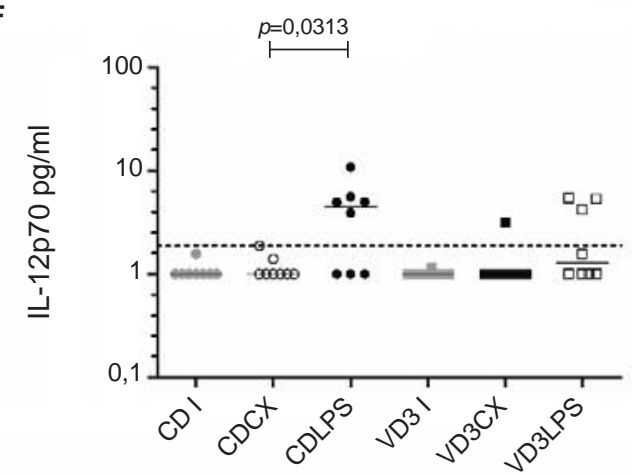

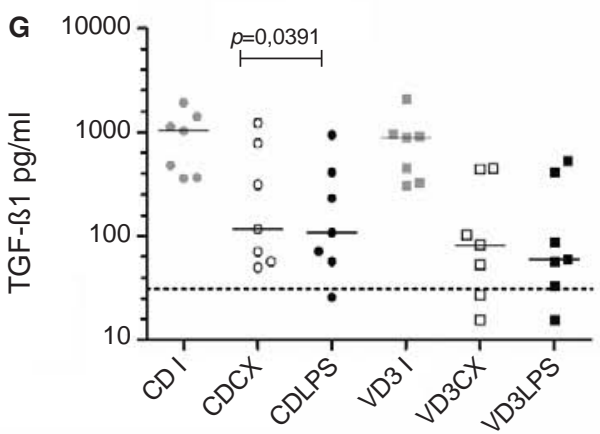

Figura 3. Perfil de citocinas secretadas por células dendríticas con vitamina D3 (CD VD3). Se obtuvieron los sobrenadantes de cultivo de cada población de células dendríticas y se conservaron a $-20^{\circ} \mathrm{C}$ hasta la cuantificación de las citocinas $(\mathbf{A})$ IL-1 $\beta$, (B) IL-8, (C) IL-10, (D) IL-6, (E) TNF-a, (F) IL-12p70 y (G) TGF $\beta-1$. Los datos representan experimentos independientes de un total de seis a ocho. La línea horizontal representa la mediana. Las diferencias entre los datos no pareados y los pareados se determinaron con las pruebas de Mann-Whitney y de Wilcoxon, respectivamente. El valor de $\mathrm{p}<0,05$ se consideró significativo. 
flujo. En algunos experimentos se utilizó TGF- $\beta 1$ más IL-2 recombinante como control positivo de inducción de LTreg (no se presenta el dato).

Los análisis mostraron que ninguna de las condiciones generó cambio en la inducción de LTreg vírgenes $\left(\mathrm{CD}^{+}{ }^{+} \mathrm{CD} 45 \mathrm{RA}^{\mathrm{hi}} \mathrm{CD} 25^{\mathrm{low}} \mathrm{FoxP} 3^{+}\right)$. Sin embargo, cuando se analizó la frecuencia de los LTreg activados $\left(\mathrm{CD}^{+}{ }^{+} \mathrm{CD} 45 \mathrm{RA}^{\text {low }}{ }^{\mathrm{CD}} 25^{\mathrm{hi}} \mathrm{FoxP}^{+}\right)$, se observó un incremento significativo en los cocultivos generados con células dendríticas sin madurar, en comparación con los que contenían células dendríticas maduradas, generadas con o sin vitamina D3 (figura 4), aunque se evidenció una tendencia de aquellas inmaduras generadas la vitamina D3 a estimular un alto porcentaje de LTreg activados. Este efecto no se observó en las células dendríticas tratadas con vitamina D3 y maduradas con lipopolisacáridos.

\section{Discusión}

En numerosos estudios en modelos de ratón se ha demostrado que las células dendríticas tolerogénicas tienen un gran potencial terapéutico, ya que pueden inhibir el rechazo y prolongar la supervivencia de los aloinjertos, prevenir la enfermedad de injerto contra huésped e inhibir diversas enfermedades autoinmunitarias (9). Estas investigaciones han permitido evidenciar la eficiencia de las células dendríticas tolerogénicas in vivo, aprovechando la facilidad de generarlas a partir de monocitos de sangre periférica en cultivos in vitro (10). Sin embargo, es importante resaltar que, para que estas células dendríticas se puedan emplear en estudios clínicos en humanos, se debe garantizar su estabilidad fenotípica y funcional, ya que en un contexto biológico son diversos los factores que pueden interactuar con ellas y alterar las características tolerogénicas, lo cual tiene un efecto directo en la polarización de la respuesta T. Por esta razón, a diferencia de otros estudios, en este modelo se usó una gran concentración de lipopolisacáridos que no afectara la viabilidad celular y permitiera simular un ambiente netamente inflamatorio para, así, evaluar su impacto sobre las características de las células dendríticas generadas con vitamina D3.

En un gran número de publicaciones se demuestra claramente que la vitamina D3 y sus análogos pueden modular el fenotipo y la función de las células dendríticas (1,4-5,7). En algunos de estos estudios se ha comprobado que el tratamiento in vitro de células dendríticas generadas de monocitos y moduladas con vitamina D3 conduce a cambios en la expresión de marcadores de maduración y moléculas coestimuladoras. A pesar de las variaciones metodológicas desarrolladas en el presente estudio, los resultados concernientes al efecto de la vitamina D3 en el fenotipo de las células dendríticas coinciden con lo reportado en la literatura científica, ya que estas conservaron el CD14, al igual que una baja expresión de HLA-DR, CD83 y CD86.

Un hallazgo fundamental en este trabajo fue la producción de citocinas promotoras de la reacción inflamatoria (IL-1 $\beta$ e IL-8) por parte de las células dendríticas generadas en presencia de vitamina D3 y maduradas con lipopolisacáridos, lo cual es un aspecto fundamental que debe evaluarse si se las quiere emplear terapéuticamente.
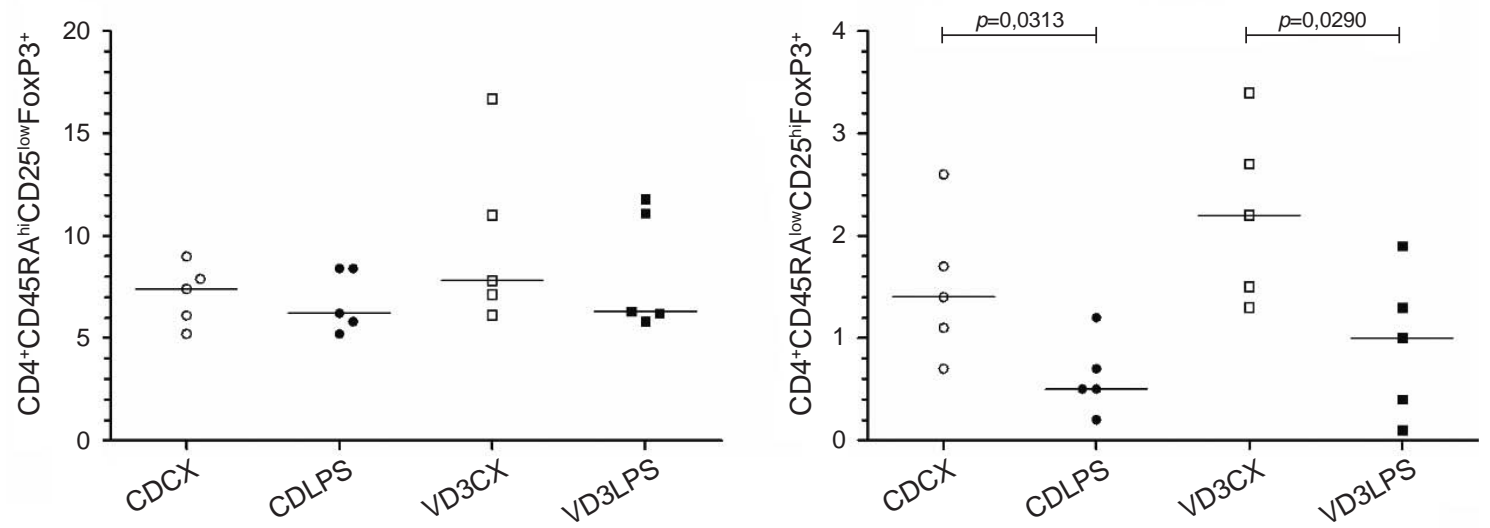

Figura 4. Frecuencia de linfocitos $T$ reguladores (LTreg) generados en cocultivos con células dendríticas (CD). Se obtuvieron LTreg vírgenes (CD4+CD45RA ${ }^{\text {hi }} C D 25^{\text {low }}$ FoxP3+) y LTreg activados (CD4+CD45RA $\left.{ }^{\text {low }} C D 25^{\text {hi }} F o x P 3+\right)$ en el cocultivo con células dendríticas generadas en ausencia o en presencia de vitamina D3 (VD3), maduradas con lipopolisacáridos (LPS) y sin madurar. Las diferencias entre los datos se determinaron con la prueba de Wilcoxon. Una $p<0,05$ se consideró significativa. 
La inducción de IL-1 $\beta$ es interesante puesto que esta citocina se ha asociado con la activación y la regulación del inflamosoma (11). Hasta donde se sabe, este es el primer reporte en el que se describe la inducción de esta citocina con células dendríticas generadas en presencia de vitamina D3. Al igual que en este estudio, en un modelo de macrófagos tratados con vitamina D3 se observó la inducción de IL1- $\beta$ como reacción a la infección con Mycobacterium tuberculosis, así como el incremento del ARNm (12).

Teniendo en cuenta las expectativas sobre un eventual uso de células dendríticas moduladas con vitamina D3 para el tratamiento de enfermedades autoinmunitarias o para evitar el rechazo a los trasplantes, así como el incremento en la producción de IL-1 $\beta$ que se registró en este estudio frente al estímulo inflamatorio simulado por la alta concentración de lipopolisacáridos, se deben explorar más a profundidad los mecanismos de producción y regulación de la IL-1 $\beta$ por parte de las células dendríticas generadas con vitamina D3.

La producción predominante de IL-10 en las células dendríticas generadas en presencia de vitamina D3, sin madurar y maduradas, se ha reportado en los estudios de varios autores con protocolos similares $(13,14)$ y, conjuntamente con el fenotipo tolerogénico, se la ha relacionado con la inducción de un grupo de LTreg denominado Tr1 (15).

Asimismo, se encontró un incremento significativo en los niveles de la IL-8 en los sobrenadantes de células dendríticas tratadas con vitamina D3 y maduradas con lipopolisacáridos, en comparación con las células maduradas no tratadas con vitamina D3. Este mismo hallazgo fue reportado en un modelo de células dendríticas tratadas con dexametasona más vitamina D3, lo que sugiere la participación favorable de esta citocina en la migración celular (16). En un estudio del 2013 (17) en un modelo experimental con la línea celular de monocitos humanos THP-1 tratados previamente con un análogo de la vitamina D3 (22-oxicalcitriol; OCT), se observó un aumento en la producción de IL-8 en reacción a varios ligandos de receptores TLR (Toll-Like Receptors) y NLR (Nod-Like Receptors), siendo mayor la asociada a los ligandos de TLR3, TLR4 y TLR2.

En cuanto a la producción de IL-12p70 y TNF-a, se encontró una tendencia a su disminución en las células dendríticas generadas en presencia de vitamina D3 y maduradas con lipopolisacáridos. La disminución de citocinas promotoras de la reaccción inflamatoria, como la IL-12 y la TNF-a, es una característica descrita claramente en las células dendríticas humanas y de ratón tratadas con vitamina D3, lo cual se asocia con su baja capacidad de inducir reacciones del tipo de Th1 (4-5).

Considerando el papel que tiene el TGF- $\beta 1$ en la inducción de LTreg (18), se analizó esta citocina en las poblaciones y se encontró una tendencia a la disminución en las células dendríticas tratadas con vitamina D3, resultado que refleja lo reportado por van der Aar, et al., en su estudio (5), en el cual se determinó el efecto de la vitamina D3 sobre equivalentes de células dendríticas dérmicas y en células de Langerhans generadas in vitro a partir de monocitos. Estos autores encontraron que el tratamiento de las células dendríticas dérmicas con vitamina D3 inducía LTreg FoxP3- mediante un mecanismo dependiente de IL-10, mientras que las células de Langerhans inducían Treg FoxP3+ mediante TGF- $\beta 1$. En el 2001, Canning, et al. (19), detectaron una disminución en la producción de TGF- $\beta$ en un modelo de células dendríticas generadas a partir de monocitos en presencia de $10^{-8} \mathrm{M}$ de vitamina D3 durante una semana, tal como sucedió en este estudio.

Por otra parte, teniendo en cuenta el papel de las células dendríticas dérmicas caracterizadas por la expresión de CD141 y CD14, por la secreción constitutiva de IL-10 y por la capacidad de inducir LTreg (6), es interesante resaltar cómo, según los resultados de Chu, et al. (6), este modelo en el que la vitamina D3 funciona como un inductor del fenotipo y la función de las células dendríticas dérmicas CD141+ podría emplearse para obtener gran cantidad de estas células y usarlas en la inducción de tolerancia con fines clínicos.

Con base en un hallazgo controversial reportado en el trabajo de Haniffa, et al., en 2012 (7), con relación al perfil de las citocinas, se planteó que, al ser estimuladas mediante un ligando de TLR3, las células dendríticas dérmicas CD141 ${ }^{\text {hi }}$ producían gran cantidad de TNFa y, además, disminuían la producción de IL-1 $\beta$, IL-6, IL-8 e IL-10 cuando eran estimuladas con un ligando de TLR3 o de TLR4, dato que no coincide con lo reportado por Chu, et al. (6). Dados estos resultados contradictorios, Haniffa, et al., plantearon que la caracterización de células dendríticas reportadas por Chu, et al., probablemente correspondía a células dendríticas CD14+ sanguíneas, las cuales también expresan CD141 y que, según su cuantificación de citocinas, eran las productoras de IL-10, así como de IL-1 $\beta$ 
e IL-6, lo cual refleja en parte el perfil de citocinas registrado en el presente estudio a partir de las células dendríticas obtenidas con la estrategia metodológica planteada por $\mathrm{Chu}$, et al., para generar células dendríticas in vitro que semejen las características fenotípicas y funcionales de las células dendríticas dérmicas CD141+. Sin embargo, una posible explicación que relaciona las células dendríticas CD14+ CD141+ sanguíneas y las células dendríticas dérmicas CD141 ${ }^{\mathrm{hi}}$ aisladas de muestras de piel, es que las primeras son precursoras de las que se encuentran en la dermis (7). Es importante aclarar que Chu, et al., no describen un panel de citocinas más amplio, vacío que en este estudio se quiso aprovechar cuantificando citocinas adicionales que permitieran obtener información sobre la caracterización funcional de las células dendríticas generadas bajo el tratamiento con vitamina D3 y, así, ampliar la hipótesis planteada por Haniffa, et al.

Además de lo anotado, en varios estudios se ha reportado que la vitamina D3 promueve la inducción de LTreg por modulación en el fenotipo y la función de las células dendríticas (20). En este estudio se encontró que las células dendríticas generadas en presencia de vitamina D3 sin madurar presentaron un tendencia a inducir con mayor frecuencia LTreg activados; sin embargo, este efecto se vio revertido cuando las células dendríticas maduraron con lipopolisacáridos, lo cual puede explicarse por los cambios funcionales asociados a la producción de citocinas promotoras de estados inflamatorios en este tipo de células, y tendría que evaluarse más detalladamente para su uso en un contexto clínico, con el fin de garantizar la estabilidad de las células dendríticas y de los linfocitos $T$ generados en su presencia.

Se requiere, no obstante, hacer más estudios experimentales para establecer la caracterización funcional de los linfocitos $T$ generados en presencia de células dendríticas moduladas con vitamina D3, ya que el fenotipo regulador asociado a la expresión de CD25 y FoxP3 puede ser inducido en los linfocitos T CD4 vírgenes tras la activación, lo cual dificulta la identificación de la población pura de LTreg FoxP3+ (21).

En conclusión, la generación de células dendríticas a partir de monocitos y en presencia de vitamina D3 bajo las condiciones experimentales de este estudio, indujo en ellas un fenotipo 'semimaduro' asociado con la baja expresión de moléculas coestimuladoras y con la conservación del marcador
CD14. Además, al comparar esta población con las células dendríticas generadas sin vitamina D3, se observaron diferencias en el perfil de citocinas secretado; en este sentido, cabe destacar la producción de IL-10 asociada a las células dendríticas tolerogénicas, así como el incremento de IL-1 $\beta$ e IL-8, descritas como citocinas promotoras de la reacción inflamatoria. Sin embargo, las células dendríticas sin madurar moduladas con vitamina D3 presentaron una tendencia a incrementar la frecuencia de LTreg activados, efecto que se vio revertido al madurarse por la acción de los lipopolisacáridos.

\section{Agradecimientos}

A Manuel Franco y Juanita Ángel, del Instituto de Genética Humana de la Facultad de Medicina de la Pontificia Universidad Javeriana, por su aporte a la discusión de los resultados obtenidos, así como al programa de Jóvenes Investigadores e Innovadores de Colciencias, 2012 (ID PPTA 5315).

\section{Conflicto de intereses}

Ninguna de las autores declara tener conflicto de intereses de tipo financiero, político o académico para el presente trabajo.

\section{Financiación}

Este proyecto fue financiado por la Pontificia Universidad Javeriana (ID PROY 004496).

\section{Referencias}

1. Nikolic T, Roep BO. Regulatory multitasking of tolerogenic dendritic cells - lessons taken from vitamin d3-treated tolerogenic dendritic cells. Front Immunol. 2013;4:1-13. http://dx.doi.org/10.3389/fimmu.2013.00113

2. Morelli AE, Thomson AW. Tolerogenic dendritic cells and the quest for transplant tolerance. Nat Rev Immunol. 2007;7:610-21. http://dx.doi.org/10.1038/nri2132

3. Rutella S, Danese S, Leone G. Tolerogenic dendritic cells: Cytokine modulation comes of age. Blood. 2006;108:143540. http://dx.doi.org/10.1182/blood-2006-03-006403

4. Unger WW, Laban S, Kleijwegt FS, van der Slik AR, Roep BO. Induction of Treg by monocyte-derived DC modulated by vitamin D3 or dexamethasone: Differential role for PD-L1. Eur J Immunol. 2009;39:3147-59. http://dx.doi.org/10.1002/ eji.200839103

5. van der Aar AMG, Sibiryak DS, Bakdash G, van Capel TMM, van der Kleij HP, Opstelten DJE, et al. Vitamin D3 targets epidermal and dermal dendritic cells for induction of distinct regulatory T cells. J Allergy Clin Immunol. 2011;127: 1532-40. http://dx.doi.org/10.1016/j.jaci.2011.01.068

6. Chu CC, Ali N, Karagiannis P, Di Meglio P, Skowera A, Napolitano L, et al. Resident CD141 (BDCA3)+ dendritic cells in human skin produce $\mathrm{IL}-10$ and induce regulatory $\mathrm{T}$ cells that suppress skin inflammation. J Exp Med. 2012;209:935-45. http://dx.doi.org/10.1084/jem.20112583 
7. Haniffa M, Shin A, Bigley V, McGovern N, Teo P, See P, et al. Human tissues contain CD141hi cross-presenting dendritic cells with functional homology to mouse CD103+ nonlymphoid dendritic cells. Immunity. 2012;37:60-73. http:// dx.doi.org/10.1016/j.immuni.2012.04.012

8. Lyakh LA, Sanford M, Chekol S, Young HA, Roberts AB. TGF-B and vitamin D3 utilize distinct pathways to suppress IL-12 production and modulate rapid differentiation of human monocytes into CD83+ dendritic cells. J Immunol. 2005;174:2061-70. http://dx.doi.org/10.4049/jimmunol.174. 4.2061

9. Iruretagoyena MI, Sepúlveda SE, Lezana JP, Hermoso M, Bronfman M, Gutiérrez MA, et al. Inhibition of nuclear factor- $\kappa B$ enhances the capacity of immature dendritic cells to induce antigen-specific tolerance in experimental autoimmune encephalomyelitis. J Pharmacol Exp Ther. 2006;318:59-67. http://dx.doi.org/10.1124/jpet.106.103259

10. Hill M, Cuturi MC. Negative vaccination by tolerogenic dendritic cells in organ transplantation. Curr Opin Organ Transplant. 2010;15:738-43. http://dx.doi.org/10.1097/MOT. 0b013e32833f7114

11. Mariathasan S, Newton K, Monack DM, Vucic D, French DM, Lee WP, et al. Differential activation of the inflammasome by caspase-1 adaptors ASC and Ipaf. Nature. 2004;430:213-8. http://dx.doi.org/10.1038/nature02664

12. Verway M, Bouttier M, Wang TT, Carrier M, Calderón M, An BS, et al. Vitamin D induces interleukin-1 $\beta$ expression: Paracrine macrophage epithelial signaling controls $M$. tuberculosis infection. PLoS Pathog. 2013;9:1-14. http:// dx.doi.org/ 10.1371/journal.ppat.1003407

13. Penna G, Amuchastegui S, Giarratana N, Daniel KC, Vulcano M, Sozzani S, et al. 1,25-Dihydroxyvitamin D3 selectively modulates tolerogenic properties in myeloid but not plasmacytoid dendritic cells. J Immunol. 2007;178:145 53. http://dx.doi.org/10.4049/jimmunol.178.1.145
14. Steinbrink K, Wölfl M, Jonuleit H, Knop J, Enk AH. Induction of tolerance by IL-10-treated dendritic cells. J Immunol. 1997;159:4772-80.

15. Jonuleit $\mathbf{H}, \mathbf{S c h m i t t} E$. The regulatory $T$ cell family: Distinct subsets and their interrelations. J Immunol. 2003;171:632327. http://dx.doi.org/10.4049/jimmunol.171.12.6323

16. Volchenkov R, Karlsen M, Jonsson R, Appel S. Type 1 regulatory $T$ cells and regulatory $B$ cells induced by tolerogenic dendritic cells. Scand J Immunol. 2013;77:24654. http://dx.doi.org/ 10.1111/sji.12039

17. Ikeuchi T, Nakamura T, Fukumoto S, Takada H. A vitamin D3 analog augmented interleukin-8 production by human monocytic cells in response to various microberelated synthetic ligands, especially NOD2 agonistic muramyldipeptide. Int Immunopharmacol. 2013;15:15-22. http://dx.doi.org/10.1016/j.intimp.2012.10.027

18. Jonuleit $\mathbf{H}$, Schmitt $\mathbf{E}$. The regulatory $T$ cell family: Distinct subsets and their interrelations. J Immunol. 2003;171:632327. http://dx.doi.org/10.4049/jimmunol.171.12.6323

19. Canning MO, Grotenhuis K, de Wit H, Ruwhof C, Drexhage HA. 1-alpha, 25-dihydroxyvitamin D3 (1, 25 $(\mathrm{OH})(2) \mathrm{D}(3))$ hampers the maturation of fully active immature dendritic cells from monocytes. Eur $\mathrm{J}$ Endocrinol. 2001;145:351-7. http://dx.doi.org/10.1530/eje.0.1450351

20. Chambers ES, Hawrylowicz CM. The impact of vitamin D on regulatory T cells. Curr Allergy Asthma Rep. 2011;11:2936. http://dx.doi.org/10.1007/s11882-010-0161-8

21. Gavin MA, Torgerson TR, Houston E, Ho WY, StrayPedersen Ar, Ocheltree EL, et al. Single-cell analysis of normal and FOXP3-mutant human T cells: FOXP3 expression without regulatory $\mathrm{T}$ cell development. Proc Natl Acad Sci U S A. 2006;103:6659-64. http://dx.doi. org/10.1073/pnas.0509484103 